\title{
Collision Dynamics of a Single Droplet onto a Heated Dry Surface: Jet Fuel and Biofuel Mixtures
}

\author{
Pedro Pinto*1, Daniel Vasconcelos ${ }^{1}$, Daniela Ribeiro ${ }^{1}$, Jorge Barata ${ }^{1}$, André Silva ${ }^{1}$ \\ ${ }^{1}$ AEROG-LAETA, University of Beira Interior, Covilhã, Portugal \\ *Corresponding author email: pedro.miguel.moreira.pinto@ubi.pt
}

\begin{abstract}
Understanding the phenomena behind droplet impact is essential to improve the effectiveness in many industrial applications, such as fuel injection in an internal combustion engine and rapid spray cooling of hot surfaces. This study focuses on an experimental investigation on droplet impact onto a heated wall. The purpose of this work is to analyse the influence of wall temperature on the morphology of a single droplet impact and observe the possible outcomes. In these experiments, the observation of all heat regimes was possible. Since there is an urge to implement biofuels in general aviation, the fluids analysed are fuel based. The fluids used were distilled water, as a control group, $100 \%$ jet fuel, and a mixture of $50 \%$ biofuel with $50 \%$ jet fuel. This mixture corresponds to the maximum of renewable energy source fuel due to the minimum of $50 \%$ of jet fuel required by civil aviation. The impact energy was kept constant, and the Weber number was set to 320 . Furthermore, different wall temperatures were chosen $\left(25^{\circ} \mathrm{C}\right.$ $-320^{\circ} \mathrm{C}$ ) to seek every possible impact phenomenon and characterise the impact morphology. The impact dynamics were captured using a high-speed digital camera and the images were digitally processed.
\end{abstract}

\section{Keywords}

Droplet Impact, Experimental Study, Jet Fuel, Biofuel Mixtures, Heated Surface.

\section{Introduction}

Nowadays, there is a scientific consensus that the observed effects of global warming are caused by fossil fuel combustion and emissions of greenhouse gases, such as nitrous oxide $\left(\mathrm{N}_{2} \mathrm{O}\right)$, carbon dioxide $\left(\mathrm{CO}_{2}\right)$ and methane $\left(\mathrm{CH}_{4}\right)$. Additionally, the transport sector and the burning of fossil fuels are responsible for a high portion of the pollution. Therefore, developing alternatives to the commonly used combustion fuels is of major importance. According to Liang and Mudawar [1], parameters influence the phenomenon of droplet impact. These include droplet and fluid physical properties (droplet diameter, $D_{0}$, impact velocity, $U_{0}$, fluid viscosity, $\mu_{f}$, fluid density, $\rho_{f}$, and fluid surface tension, $\sigma$ ), surrounding gas properties (pressure, temperature, and flow configuration), and wall characteristics (wettability, diffusivity, surface roughness, and wall temperature, $T_{w}$ ). These parameters combined provide some dimensionless numbers that are used to define the droplet impact. The most commonly used dimensionless numbers are the Reynolds number, $R e=\left(\rho_{f} U_{0} D_{0}\right) / \mu_{f}$, and the Weber number, $W e=\left(\rho_{f} U_{0}^{2} D_{0}\right) / \sigma$. The Reynolds number is the ratio between the inertial forces and viscous forces, and the Weber number relates the inertial and surface tension forces. Additionally, there is another dimensionless parameter to characterise the impact, which is the the dimensionless time, $\tau=U_{0} t / D_{0}$, where $t$ represents the time after impact.

When a droplet impacts onto a dry non-heated solid surface, the droplet outcome depends on many factors, such as impact energy and surface properties. Earlier phases of droplet impact are controlled by the Reynolds and Weber numbers, while in the later stages, the substrate effect is more important [2]. This means that on a wettable substrate the impact can result in additional spreading, while on a partially wetting substrate with low surface energy, the droplet may recede. In a non-wetting substrate, the droplet will recede and if the surface is hygrophobic, 
the droplet may rebound [2]. Additionally, droplet spreading after an impact onto a dry surface can be accompanied by instabilities at the outer rim of the lamella. This phenomenon is termed fingering and the instabilities are called fingers [3].

Rioboo et al. [4] experimentally observed six possible scenarios of droplet impact on a dry wall: spreading, prompt splash, corona splash, receding breakup, partial rebound, and complete rebound. Spreading takes into consideration when the droplet deforms and sticks to the surface during its impacting process, without formation of secondary droplets. Prompt splash occurs when the liquid lamella disintegrates in the periphery into secondary droplets in the spreading phase. It is promoted by a higher impact energy on rough surfaces. At the end, the droplet spreads and stays on the wall. Reducing the surface tension, the liquid lamella can separate from the wall, resulting in a corona splash. The corona splash occurs on a smooth surface, where the outer rim of the expanding lamella is lifted off the surface to form a corona shaped structure, from which a high number of secondary droplets are generated. Receding breakup occurs when some tiny droplets detach from the original droplet in the receding phase. The dynamic contact angle decreases as the liquid retracts from its maximum spreading radius. If the limiting value of zero is reached, some droplets are left behind the receding lamella. The partial and complete rebound only happen when a receding phase is observed. The occurrence of this phase depends on the maximum diameter reached by the spreading droplet and the receding contact angle. For higher energetic impacts, this diameter is larger, and the maximum diameter is even larger than it would be expected, given the receding contact angle. In this case, the droplet begins to recede. The difference between whether it is complete or partial rebound is in the receding contact angle. Knowing that the receding phase is energetic enough in both cases, for lower values of receding contact angle, a partial rebound occurs and, for higher values, a complete rebound occurs [4].

\section{Effects of Surface Temperature}

The surface temperature is a very important factor that affects the outcomes of the impacting droplets. Nevertheless, the consideration of this factor introduces further complexity to the impact phenomena. Distinct heat transfer mechanisms may develop when a droplet impinges a hot surface, which depends on wall temperature, $T_{w}$, the saturation temperature (or boiling temperature) of the liquid, $T_{\text {sat }}$, and the Leidenfrost temperature, $T_{\text {Leid }} . T_{\text {Leid }}$ is the Leidenfrost temperature or the minimum evaporation temperature, which depends on many parameters such as surface and liquid properties, and impact parameters [5]. If $T_{w}<T_{\text {sat }}$, heat transfer is mostly done by conduction from the wall to the liquid and by evaporation due to mass transfer along the liquid-gas interface. When $T_{w}>T_{s a t}$, the droplet boils on the heated wall, and tiny bubbles form inside the droplet. Finally, when $T_{w}>T_{\text {Leid }}$, a thin vapour layer forms between the droplet and the wall, and heat transfer is highly reduced [6]. The wall temperature and the impact Weber number are the two most important parameters on determining the impact regime. It affects both impact dynamics and heat transfer performance [7]. Describing the several regimes is quite complex since the phenomena observed must consider each phase of the boiling regime. Bertola [8] conducted an experiment for high surface temperatures on an aluminium plate and proposed a classification based on the final outcome instead of the morphology of the droplet during impact. This includes five main impact regimes for droplet impact onto a dry heated wall: secondary atomisation, splashing, rebound, rebound with secondary atomisation, and splashing with secondary atomisation. The rebound phenomenon occurs for lower Weber numbers, while the splashing occurs for higher Weber numbers. Other investigators such as Ko and Chung [9] reported four different regimes for a droplet impact on a heated surface. They are presented in order of increasing surface temperature: film evaporation, when $T_{w}<T_{s a t}$, nucleate boiling, when $T_{s a t}<T_{w}<T_{C H F}$, transition boiling, when $T_{C H F}<T_{w}<T_{L e i d}$ and an unstable vapour layer forms between the liquid-solid interface, and film boiling, when $T_{w}>T_{\text {Leid }}$ and a stable vapour layer is formed in the liquid-solid interface that 
greatly reduces the heat flux from the wall to the droplet. $T_{C H F}$ is the critical heat flux temperature, where the droplet evaporation time is the shortest and increases up until the Leidenfrost temperature. Based on the increasing pressure in the liquid-solid interface for an impinging droplet, it was established that the Leidenfrost temperature increases for higher droplet velocities [5]. The surface temperature influences the characteristic size of secondary droplets and the splashing threshold. Since the identification of different heat regimes is mostly based on the droplet morphology, some authors define the Leidenfrost temperature as a dynamic property, $T_{L, d}$. When $T_{w}$ is above $T_{s a t}$, vapour bubbles created on the heated surface rise by buoyancy and burst on the free surface of the droplet, dispersing a high number of secondary droplets. The intensity of secondary atomisation varies according to the surface temperature and the Weber number, and the secondary droplets are not uniform in size. Secondary atomisation depends highly on the properties of the surface, specifically its thermal diffusivity. A phenomenon of secondary atomisation is the formation of jets above pagoda-like bubbles, which was reported by Cossali et al. [10]. The purpose of the present article is to visualise and analyse the effects of wall temperature and fluid properties on the different outcome of the droplet impact. The impacts considered in the present article are on dry surfaces and at a normal impact angle.

\section{Material and methods}

The experimental setup is represented in Figure 1 and is made up of four different parts: the image acquisition system (high-speed digital camera), the lighting (LED lamp and a diffusion glass), the pumping system (syringe pump and needles), and the heating system (impact surface and heating device). The high-speed digital camera is connected to a computer and placed right in front of the impact surface and the lighting. The record rate was set to $2000 \mathrm{fps}$, the shutter speed to $1 / 10240$ seconds, and the resolution of the images obtained is $1280 \times 1024$. The impact surface is made of aluminium and four embedded $250 \mathrm{~W}$ cartridge heaters heat it up from ambient temperature up to $320^{\circ} \mathrm{C}$. The pumping system is placed on the side of the assembly. It is composed of a syringe connected to a needle, and it is computer-operated to manually choose the desired pumping rate. The needles chosen were based on the desired droplet diameter and corresponding Weber number. Before the droplet impact experiments, the calibration of the surface temperature was made. Therefore, seven different temperatures were selected and measured with four thermocouples distanced by $1 \mathrm{~cm}$ in the radial direction from the centre of the impact surface. After heating up, the temperature stabilises at a lower temperature than the selected, and then the surface temperature was measured for ten minutes. In Figure 2, an example of the graphs obtained by these measurements is provided. The other temperatures tested followed the same pattern, in which they increase until reaching a peak and then dropping to the temperature in which they stabilise. Table 1 represents the

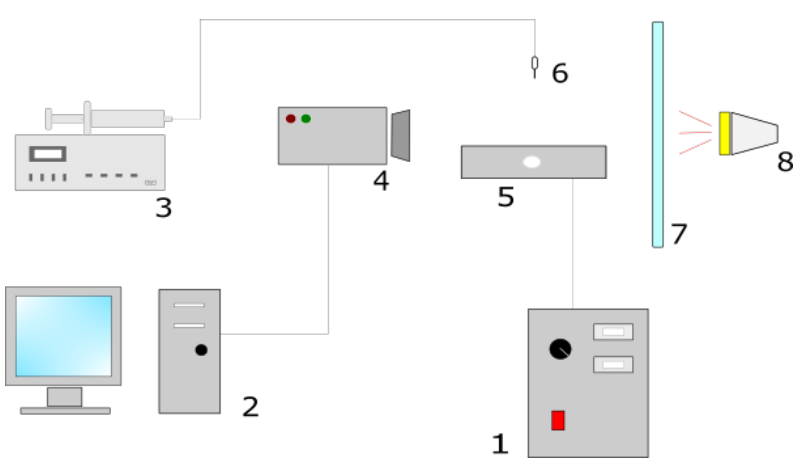

Figure 1. Diagram of the experimental setup: 1 - Heating Device; 2 - Computer; 3 - Syringe and pump; 4 High-speed digital camera; 5 - Impact surface; 6 . Dispensing needle; 7 - Diffusion glass; 8 - LED lamp.

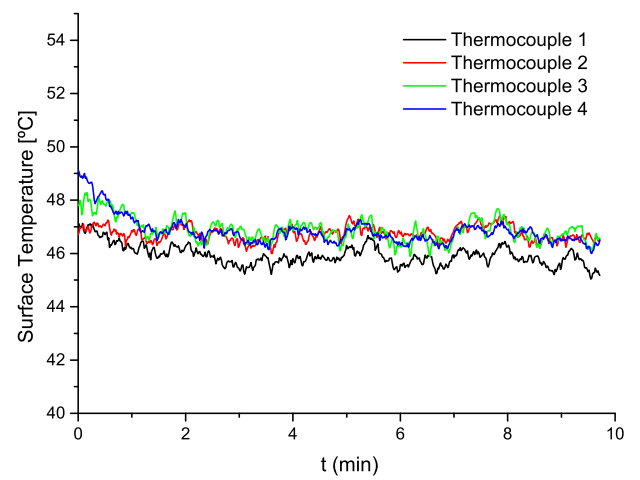

Figure 2. Surface temperature stabilisation for a selected temperature of $T_{w}=50^{\circ} \mathrm{C}$ 
measurements made and the surface temperature deviations. Each case of study was tested ten times, and before every test, the surface temperature was measured until it stabilised. Additionally, every five tests made, another measurement of the surface temperature would be made to ensure that the temperature did not vary and every impact had the same conditions.

Table 1. Values of the mean surface temperature, the standard deviation and the surface temperature variation after its stabilisation

\begin{tabular}{c|ccc}
\hline $\begin{array}{c}\text { Selected } \\
\text { Temperature } \\
{\left[{ }^{\circ} \mathrm{C}\right]}\end{array}$ & $\begin{array}{c}\text { Mean Surface } \\
\text { Temperature } \\
{\left[{ }^{\circ} \mathrm{C}\right]}\end{array}$ & $\begin{array}{c}\text { Standard } \\
\text { Deviation } \\
{\left[{ }^{\circ} \mathrm{C}\right]}\end{array}$ & $\begin{array}{c}\text { Surface } \\
\text { Temperature } \\
\text { Variation }\left[{ }^{\circ} \mathrm{C}\right]\end{array}$ \\
\hline 50 & 47 & 0.57 & {$[46.4-47.6]$} \\
100 & 91 & 1.17 & {$[89.8-92.2]$} \\
150 & 135 & 1.09 & {$[133.9-136.1]$} \\
200 & 180 & 1.87 & {$[178.1-181.9]$} \\
250 & 224 & 1.39 & {$[222.6-225.4]$} \\
300 & 267 & 3.47 & {$[263.5-270.5]$} \\
350 & 315 & 3.90 & {$[311.1-318.9]$}
\end{tabular}

The fluids properties are derived from Ribeiro et al. [11] and are presented in Table 2. The jet fuel (JF) used was Jet A-1, and the biofuel is a hydroprocessed vegetable oil (HVO) called NExBTL.

Table 2. Values of density, $(\rho)$, surface tension, $(\sigma)$, dynamic viscosity, $(\mu)$, flash point, and boiling point for the

\begin{tabular}{c|cccc}
\multicolumn{5}{c}{ fluids used. Adapted from Ribeiro [11]. } \\
\hline Fluids & $\mathrm{H}_{2} \mathrm{O}$ & $100 \% \mathrm{JF}$ & $50 \% \mathrm{JF}-50 \% \mathrm{HVO}$ & $100 \% \mathrm{HVO}$ \\
\hline$\rho\left[\mathrm{kg} / \mathrm{m}^{3}\right]\left(\right.$ at $\left.22^{\circ} \mathrm{C}\right)$ & 1000.0 & 798.0 & 792.4 & 785.2 \\
$\sigma[\mathrm{mN} / \mathrm{m}]\left(\right.$ at $\left.22^{\circ} \mathrm{C}\right)$ & 71.97 & 25.37 & 24.64 & 26.59 \\
$\mu[\mathrm{Pa} . \mathrm{s}]\left(\right.$ at $\left.22^{\circ} \mathrm{C}\right)$ & 0.00100 & 0.00112 & 0.00179 & 0.00340 \\
Flash Point $\left({ }^{\circ} \mathrm{C}\right)$ & - & 38.5 & - & 77.0 \\
Boiling Point $\left({ }^{\circ} \mathrm{C}\right)$ & 100 & $151.9-237.2$ & - & $210.5-308.0$
\end{tabular}

The droplet physical properties were calculated using a MATLAB code. To determine the droplet diameter, the vertical and horizontal length of the droplet, since the first frame that the droplet is complete until the last before impact, were calculated. Averaging these values and then averaging again for the ten experiments done, the droplet diameter was obtained. The droplet impact velocity was determined by using the last $2.5 \mathrm{~ms}$ frames before impact. The centroid position of the droplet for each frame is determined and divided by the time stamp between each frame. After calculating this for every test, the average was calculated and the impact velocity obtained.

\section{Results and discussion}

The fluid physical properties are presented in Table 3. The experimental values of the droplet diameter and impact velocity were purposely chosen to maintain the Weber number. The results are presented in four subsections according to the heat regime considered. In each subsection, an analysis of the phenomena observed and a sequence of images of the droplet impact will be presented. Additionally, it was attempted to provide the same dimensionless time for each sequence of images. However, it was not possible and only similar dimensionless time were possible to provide. Therefore, the time stamp mentioned in the text refers to a similar dimensionless time in the sequences of images.

\section{Film Evaporation}

In order to predict the influence of wall temperature on the outcome, the first analysis made is when the wall temperature equals the ambient temperature, $T_{w}=T_{a m b}=25^{\circ} \mathrm{C}$ (Figure $3(\mathrm{a}, \mathrm{b})$ ). A bubble is quickly formed right after impact, which was attributed to air entrapment due to the deformation of the liquid droplet during impact (sequence of vertical images at $\tau=0.3$ ). Afterwards, the droplets spread on the surface until reaching their maximum spreading diameter. 
Table 3. Working conditions and dimensionless numbers for the fluids used.

\begin{tabular}{c|ccccc}
\hline Fluid & $\begin{array}{c}\text { Needle Inner } \\
\text { Diameter [mm] }\end{array}$ & $\begin{array}{c}\text { Droplet } \\
\text { Diameter } \\
{[\mathrm{mm}]}\end{array}$ & $\begin{array}{c}\text { Impact } \\
\text { Velocity } \\
{[\mathrm{m} / \mathrm{s}]}\end{array}$ & We & $\mathrm{Re}$ \\
\hline $\mathbf{\mathrm { H } _ { 2 } \mathrm { O }}$ & 1.50 & $4.0 \pm 0.42$ & $2.4 \pm 0.33$ & 313 & 9527 \\
$\mathbf{1 0 0 \%} \mathrm{JF}$ & 0.84 & $2.9 \pm 0.33$ & $1.9 \pm 0.30$ & 324 & 3730 \\
$50 \% \mathrm{JF}-50 \% \mathrm{HVO}$ & 0.51 & $2.8 \pm 0.28$ & $1.9 \pm 0.23$ & 325 & 2355
\end{tabular}

When the droplet reaches its maximum spreading diameter (meaning that the contact area is the highest) the heat flux from the wall to the droplet also increases. The spreading phase for water was accompanied by instabilities called fingers $(\tau=3.0)$. Then, if the surface tension is sufficiently high, the droplet may enter a receding phase. Water has a surface tension almost three times higher than the other fluids and, for this reason, it was the only fluid entering a receding phase. In the case of water, the droplet would experience receding breakup $(\tau=36.0)$, while for the other fluids, the droplet remains in its maximum spreading diameter. Increasing the temperature, the receding phase was observed for the fuels, and the droplet would intermittently oscillate between spreading and receding until reaching its equilibrium state. Further increasing the wall temperature to a temperature where the heat flux can break the surface tension forces that keep the liquid together, the droplet breaks up after completely spreading into liquid puddles (Figure 3 (c)). These small masses of water slowly evaporate on the heated plate with few secondary atomisation, observed by the formation and bursting of jets forming on top of the droplet. Additionally, the fuels experienced evaporation of fumes ( $\tau=39.3$ ) which, according to Cen et al. [12], is called puffing.

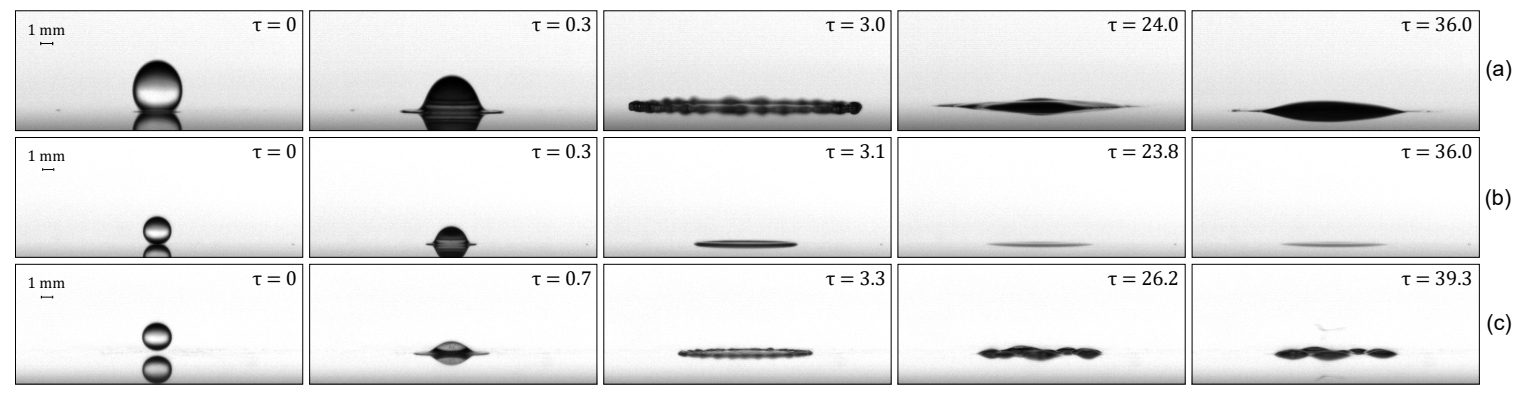

Figure 3. Droplet impact within the film evaporation regime for different fluids. (a) Water impact at $T_{w}=25^{\circ} \mathrm{C}$. (b) $50 \% \mathrm{JF}-50 \% \mathrm{HVO}$ at $T_{w}=25^{\circ} \mathrm{C}$. (c) $100 \% \mathrm{JF}$ impact at $T_{w}=150^{\circ} \mathrm{C}$.

\section{Nucleate Boiling}

Figure 4 shows the droplet impact of different fluids in the nucleate boiling regime. In the first stages of the spreading phase, instabilities due to the incipience of boiling that did not exist before now appear for jet fuel and the $50 \%-50 \%$ mixture $(\tau=3.3)$. After the droplet achieves its maximum spreading diameter, the heat flux increases which produces vapour bubbles that burst on top of the droplet and create intense secondary atomisation. Additionally, the secondary atomisation can be produced by the formation of thin jets on the top of vapour bubbles, which were reported by Cossali et al. [10] and are reported in Figure 5. Additionally, in this regime, the fuel mixtures experienced puffing. For the mixture of $50 \%-50 \%$, the existence of a receding phase and the gradually decreasing secondary atomisation ( $\tau=28.5$ to $\tau=118.8$ in (c)) suggests that the droplet is evolving to a film evaporation regime, implying that there are two regimes. This can be explained by the difference between the two boiling points of the fluids. Since the boiling point of HVO (around $T_{\text {sat }}=285^{\circ} \mathrm{C}$ ) is so much higher than jet fuel $\left(T_{\text {sat }}=175^{\circ} \mathrm{C}\right)$, two different regimes can coexist. 


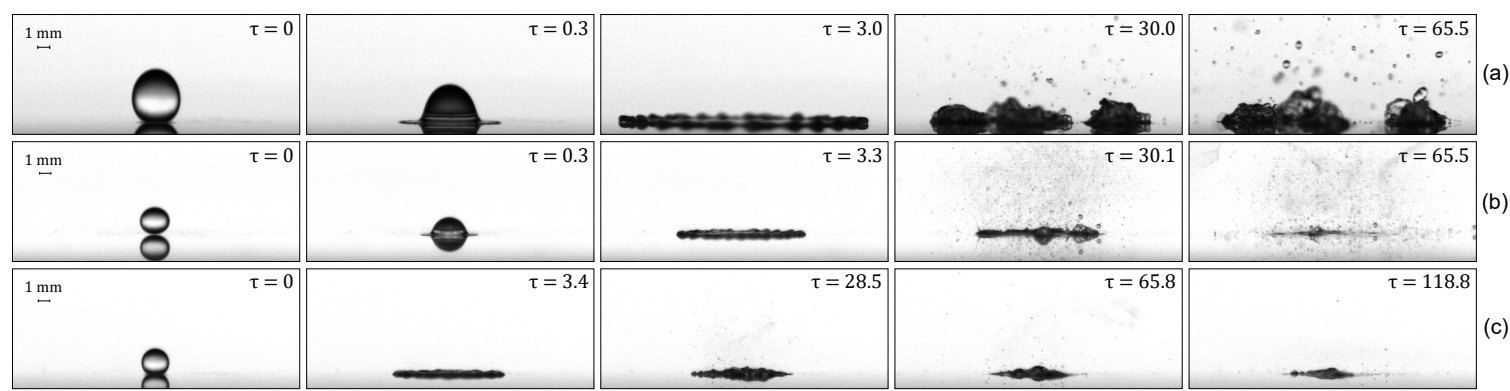

Figure 4. Droplet impact within the nucleate boiling regime for different fluids. (a) Water impact at $T_{w}=110^{\circ} \mathrm{C}$. (b) $100 \% \mathrm{JF}$ impact at $T_{w}=175^{\circ} \mathrm{C}$. (c) $50 \% \mathrm{JF}-50 \% \mathrm{HVO}$ at $T_{w}=250^{\circ} \mathrm{C}$.

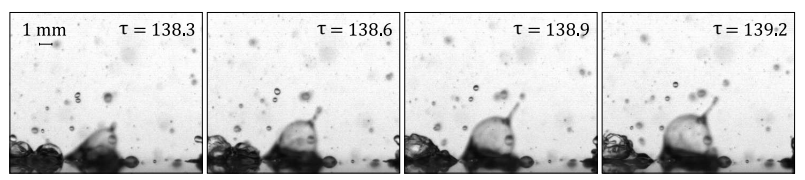

Figure 5. Formation of pagoda-like bubbles on a water droplet within the nucleate boiling regime $\left(T_{w}=110^{\circ} \mathrm{C}\right)$

\section{Transition Boiling}

The droplet impact within the transition boiling regime is represented in Figure 6. In this regime, the droplet contacts with the surface intermittently, and the Leidenfrost phenomenon is visible, in which a tiny vapour layer forms between the droplet and the surface. This vapour layer reduces drastically the heat flux from the surface to the droplet, which increases the droplet evaporation time. When the droplet impacts and spreads, it boils on the surface $(\tau=6.0)$ with intense secondary atomisation and, in the case of the fuels, accompanied with puffing. In the receding phase, the fluid coalesces to form bigger droplets $(\tau=24.0)$. After the droplets are completely formed, the secondary atomisation and puffing stops, and the remaining daughter droplets rebound on the heated surface $(\tau=48.8)$. However, if the heat flux is not enough to sustain the vapour layer, the droplet can burst on the bottom side of the droplet and breakup into multiple droplets, producing secondary atomisation. Multiple vapour bubbles can be seen inside the fully formed droplets in later stages $(\tau=48.8)$ that can lead to the production of more secondary atomisation if the bubbles burst from the droplet. For the mixture of $50 \%-50 \%$, nucleate boiling is occurring at the same time as transition boiling. At $(\tau=29.9)$, it can be observed that larger droplets are ejected from the secondary atomisation, which rebound on the heated surface $(\tau=48.9)$.

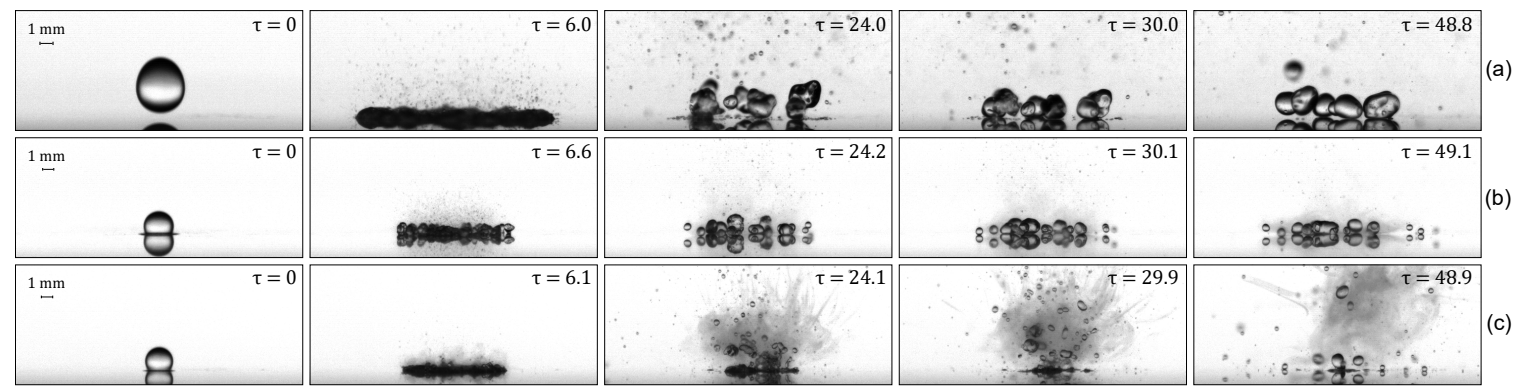

Figure 6. Droplet impact within the transition boiling regime for different fluids. (a) Water impact at $T_{w}=135^{\circ} \mathrm{C}$. (b) $100 \% \mathrm{JF}$ impact at $T_{w}=200^{\circ} \mathrm{C}$. (c) $50 \% \mathrm{JF}-50 \% \mathrm{HVO}$ at $T_{w}=275^{\circ} \mathrm{C}$.

\section{Film Boiling}

Figure 7 corresponds to the droplet impact of the different fluids within the film boiling regime. Above the Leidenfrost temperature, the film boiling regime is reached and the droplet no longer contacts the wall, hence called a non-wetting regime. This temperature represents the max- 
imum droplet evaporation time due to the drastically reduced heat flux from both interfaces. Many investigators observed rebound in this regime for lower Weber numbers. However, in these experiments, due to the moderate Weber number, the droplet always experienced splashing. Immediately after impact, the droplet undergoes a prompt splash, where the droplet breaks up in the rim of the lamella $(\tau=0.6)$ to eject smaller droplets radially. The secondary droplets are produced only in the radial direction and never in the vertical direction, compared to lower temperatures. Although the number of bubbles inside the droplets is reduced significantly when compared to the transition boiling regime, some bubbles can still be observed. Additionally, due to the absence of contact between the wall and the droplet, there is no more puffing. Moreover, in some cases, it was observed that the droplets could coalesce while rebounding on the surface. For the mixture of $50 \%-50 \%$, larger droplets are concentrated in the centre of the impact, while the other fluids do not seem to follow any particular pattern.

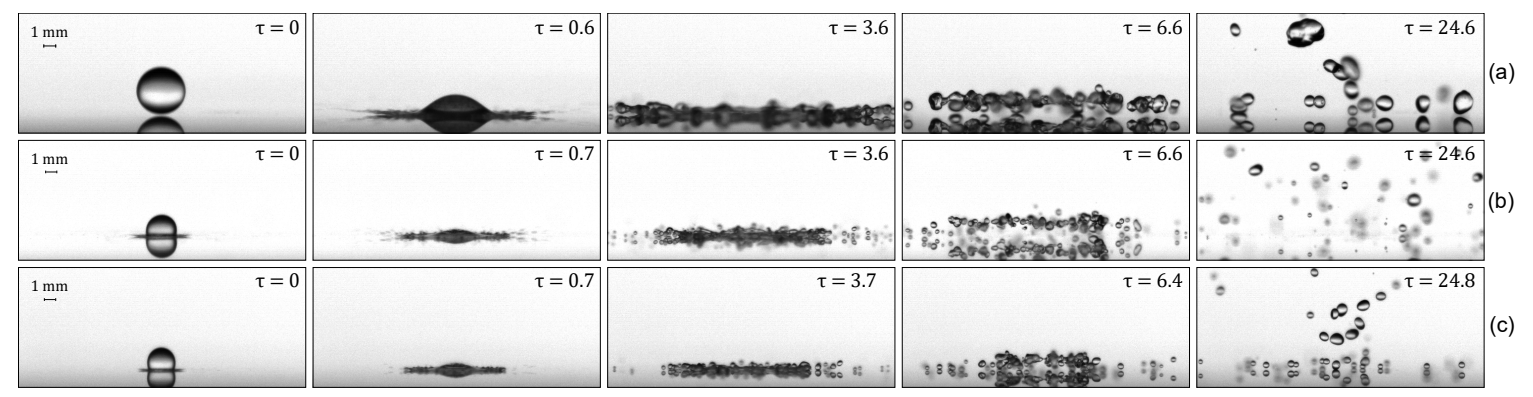

Figure 7. Droplet impact within the transition boiling regime for different fluids. (a) Water impact at $T_{w}=320^{\circ} \mathrm{C}$. (b) $100 \% \mathrm{JF}$ impact at $T_{w}=240^{\circ} \mathrm{C}$. (c) $50 \% \mathrm{JF}-50 \% \mathrm{HVO}$ at $T_{w}=320^{\circ} \mathrm{C}$.

After the experiments, it was possible to trace a map regime for these three fluids based on wall temperature while keeping a constant Weber number (Figure 8). The mixture has the highest saturation temperature, therefore, it has the widest range of temperatures in the film evaporation regime. The nucleate boiling regime is similar in all cases. Comparing the transition boiling regime, distilled water has the widest range of temperatures, while the other fluids experience the same regime in similar ranges. The Leidenfrost temperature of $100 \% \mathrm{JF}$ is the lowest, which means that the film boiling regime begins earlier, while the mixture and distilled water have similar Leidenfrost temperatures, and therefore, the film boiling regime begins at similar temperatures.

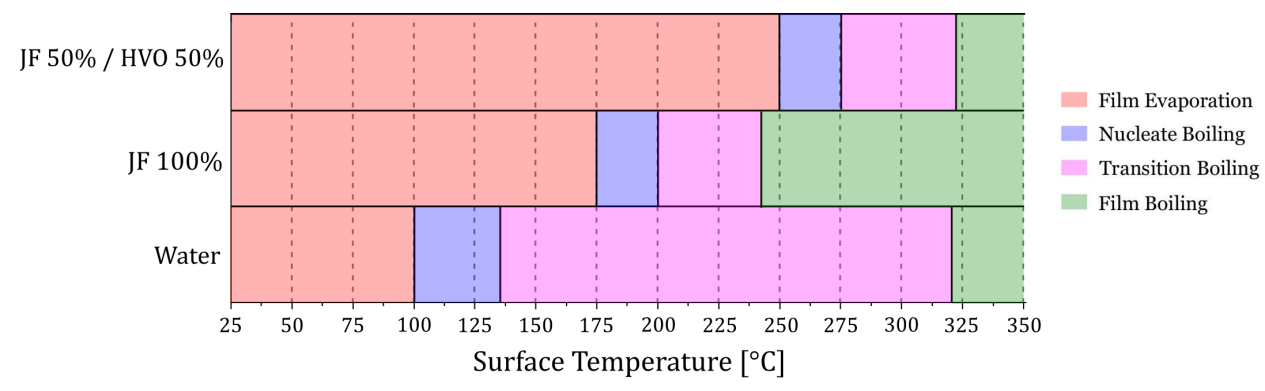

Figure 8. Regime map for different fluids with the same Weber number.

\section{Conclusions}

The present work studies the morphology of droplet impact for three different fluids while maintaining a constant impact energy. When $T_{w}=T_{a m b}$, fingering was only observed for distilled water, and the receding phase is non-existent for fluids with low surface tension, in this case, $100 \% \mathrm{JF}$ and $50 \% \mathrm{JF}-50 \% \mathrm{HVO}$. However, increasing wall temperature promotes the occurrence of this phase. Further increasing wall temperature, the surface tension forces cannot keep up with the heat flux, and the droplet breaks into liquid puddles that slowly evaporate on 
the heated plate. In the nucleate boiling regime, the notable difference was for the $50 \%-50 \%$ mixture where the droplet experiences nucleate boiling regime in the first stages but slowly evolves into a film evaporation regime. Additionally, pagoda-like bubbles are reported and are well visible in this work. In the transition boiling regime, two regimes were also observed for the mixture of $50 \%-50 \%$, in this case, transition and nucleate boiling. Both in the nucleate and transition boiling regimes, the evaporation of fumes was observed and is called puffing. In the film boiling regime, the major difference was in the concentration of larger droplets after impact. While the $100 \%$ JF and distilled water did not follow any particular pattern, the $50 \%-$ $50 \%$ mixture constantly had larger droplets in the centre of the impact.

\section{Acknowledgements}

The present work was performed under the scope of Laboratório Associado em Energia Transportes e Aeronáutica (LAETA) activities, and it was supported by Fundação para a Ciência e a Tecnologia (FCT) through the project UIDB/50022/2020, and the grant sponsored by Fundação para a Ciência e a Tecnologia SFRH/BD/140009/2018 and SFRH/BD/143307/2019.

\section{Nomenclature}

$D_{0}, U_{0} \quad$ Droplet impact parameters (Diameter [m]; Velocity [m/s])

Re Reynolds number [-]

$t \quad$ time [s]

$T_{a m b}, T_{\text {sat }}$ Ambient temperature $\left[{ }^{\circ} \mathrm{C}\right]$; Saturation temperature $\left[{ }^{\circ} \mathrm{C}\right]$

$T_{C H F} \quad$ Critical heat flux temperature $\left[{ }^{\circ} \mathrm{C}\right]$

$T_{\text {Leid }}, T_{L, d}$ Leidenfrost temperature $\left[{ }^{\circ} \mathrm{C}\right]$; Dynamic Leidenfrost temperature $\left[{ }^{\circ} \mathrm{C}\right]$

$T_{w} \quad$ Surface temperature $\left[{ }^{\circ} \mathrm{C}\right]$

We Weber number [-]

$\mu_{f}, \rho_{f}, \sigma \quad$ Kinematic viscosity [Pa.s]; Density $\left[\mathrm{m}^{3} / \mathrm{kg}\right]$; Surface tension [N/m]

$\tau \quad$ Dimensionless time [-]

\section{References}

[1] Liang, G., and Mudawar, I., 2016, International Journal of Heat and Mass Transfer, 101, pp. 577-599.

[2] Ersoy, N., and Eslamian, M., 2020, Experimental Thermal and Fluid Science, 112, pp. 109977.

[3] Yarin, A.L, 2006, Annual Review of Fluid Mechanics, 38, pp. 159-192.

[4] Rioboo, R., Tropea, C., and Marengo, M., 2001, Atomization and Sprays, 11 (2), pp. 155165.

[5] Roisman, I.V., Breitenbach, J., and Tropea, C., 2018, Journal of Fluid Mechanics, 842, pp. 87-101.

[6] Liang, G., and Mudawar, I., 2017, International Journal of Heat and Mass Transfer, 106, pp. 103-126.

[7] Bernardin, J.D., Stebbins, C.J., and Mudawar, I., 1997, International Journal of Heat and Mass Transfer, 40 (2), pp. 247-267.

[8] Bertola, V., 2015, International Journal of Heat and Mass Transfer, 85, pp. 430-437.

[9] Ko, Y.S., and Chung, S.H., 1996, Experiments in Fluids, 21 (2), pp. 118-123.

[10] Cossali, G.E., Marengo, M., and Santini, M., 2005, Experimental Thermal and Fluid Science, 29 (8), pp. 937-946.

[11] Ribeiro, D.F.S., Silva, A.R.R., and Panão, M.R.O., 2020, Applied Sciences, 10 (19), 6698.

[12] Cen, C., Wu, H., Lee, C., Fan, L., and Liu, F., 2019, International Journal of Heat and Mass Transfer, 132, pp. 130-137. 